\title{
Inclusão do tênis na formação de professores de educação física: experiências de ensino e de reconstrução em um curso de licenciatura
}

\section{Tennis inclusion in the training of physical education teachers: teaching experiences and reconstruction in the degree course}

\author{
Wesly Otoni Ferreira ${ }^{1}$, Bianca Henriques de Oliveira ${ }^{1}$, Vinicius do Carmo Fontana², \\ Mariana Zuaneti Martins ${ }^{1}$ \\ ${ }^{1}$ Universidade Federal do Espírito Santo (UFES), Vitória/ES, Brasil \\ 2 Universidade Vila Velha (UVV), Vila Velha/ES, Brasil
}

\section{HISTÓRICO DO ARTIGO}

Recebido: 29 março 2020

Revisado: 28 maio 2020

Aprovado: 31 maio 2020

\section{PALAVRAS-CHAVE:}

Educação Física Escolar;

Pedagogia do Esporte; Tênis.

\section{KEYWORDS:}

School Physical Education; Sport Pedagogy; Tennis.

\section{RESUMO}

INTRODUÇÃO: Nesse artigo expomos o desenvolvimento de uma experiência vinculada ao tênis no curso de licenciatura em educação física.

OBJETIVO: O objetivo foi, com base nos pressupostos da pedagogia do esporte, propor uma série de jogos partindo do voleibol, esporte conhecido, para o tênis. Em segundo lugar, promover a problematização da "elitização" da modalidade e esboçar possibilidades para confeccionar bolas e raquetes para o jogo do tênis. MÉTODOS: Esse relato de experiência foi desenvolvido na disciplina de pedagogia do esporte do curso de licenciatura em educação física, com alunos/as do $6^{\circ}$ semestre. Era uma turma de 26 alunos, que reunia diferentes níveis de habilidades e vivências esportivas, todos tinham algum contato com o esporte, mas nenhum com tênis. Foram realizadas 4 aulas, num total de 16 horas. Ao final da experiência, realizamos entrevista semiestruturada com 6 alunos/as que participaram das aulas e da confecção e teste dos materiais. RESULTADOS: Os alunos/as demonstraram um envolvimento e mobilização com a proposta de série de jogos de uma prática conhecida, voleibol, para uma menos conhecida, o tênis. Desenvolveram suas propostas de confecção de materiais com criatividade e nos seus relatos afirmaram ser uma possibilidade muito factível de se promover esse tipo de aula nas escolas, ainda que a ausência dos materiais oficiais possa ser sentida. Esse fator, ao mesmo tempo em que promoveu um certo desconforto, por jogar sem os "materiais oficiais", também permitiu problematizar a ideia de que a elitização é inescapável à prática do tênis.

CONCLUSÃO: Essas possibilidades, inseridas no curso de formação, permitiram ao licenciando vislumbrar possibilidades de atuação com a modalidade na prática pedagógica cotidiana na escola.

\section{ABSTRACT}

BACKGOUND: In this article we expose the development of an experience linked to tennis in the physical education undergraduate school.

OBJECTIVE: Based on the assumptions of sport pedagogy, we aimed to offer a series of games starting from volleyball, a well-known sport, for tennis. Second, to promote the problematization of the "elitization" of the sport and to outline possibilities for making balls and rackets for the game of tennis.

METHODS: This experience report was developed in the sport pedagogy discipline of the physical education degree course, with 6th semester students. It was a group that brought together different levels of skills and sports experiences, everyone had experiences with sports, but with few modalities. Four classes were held, for a total of 16 hours, between practical and theoretical activities. At the end of the experiment, we conducted a semi-structured interview with 6 students who participated in the classes and the making and testing of the materials.

RESULTS: The students showed involvement and mobilization with the offered content (proposed series of games from a known practice, volleyball, to a lesser known one, tennis). They developed their proposals for making materials with creativity and in their reports they said it was a very feasible possibility of promoting this type of class in schools, even though the absence of official materials can be felt.

CONCLUSION: These possibilities, inserted in the training course, allow the undergraduate student to glimpse possibilities of action with the modality in the daily pedagogical practice at school. 


\section{INTRODUÇÃo}

No Brasil, o tênis é reconhecidamente um esporte "elitizado", sendo identificado como prática corporal para pessoas de alto poder aquisitivo (SILVA et al, 2017). Como consequência, poucas têm acesso a modalidade, de modo que ela sequer aparece nos levantamentos de práticas corporais dos brasileiros (MINISTÉRIO DO ESPORTE, 2016; PNUD, 2017). Resulta disso também, que poucos cursos de educação física tratam dessa modalidade esportiva na trajetória formativa de um graduando ou licenciando. De um universo de 20 cursos de bacharelado em Educação Física de universidades públicas federais, apenas 2 ofertavam uma disciplina de tênis.

Dias e colaboradores (2002) relatam que a ausência de profissionais qualificados, a falta de materiais e de infraestrutura específica para o desenvolvimento da modalidade têm sido apontados pelos coordenadores de cursos como os principais responsáveis por este cenário. Isso contribui, sem dúvida, para um distanciamento com o meio acadêmico, e faz com que alunos/as que não possuam prática com a modalidade anteriormente tenham dificuldade em ministrar aulas, mesmo que reúnam explicações ou correlações em outras disciplinas no decorrer do curso (MILISTEDT et al., 2015). Diante desse quadro, relatamos uma experiência que buscou enfrentar esses dois desafios: em primeiro lugar, tratar da tematização pedagógica da iniciação ao tênis; e, em segundo, problematizar sua "elitização" e transpor didaticamente a barreira da ausência de materiais e infraestrutura na escola para ensinar a modalidade.

Tratar do tênis na educação física escolar tem por objetivo também diversificar as oportunidades de aprendizagem das práticas esportivas aos estudantes. Via de regra, nas escolas, ainda prevalece a monocultura esportiva do futsal e, quando muito, geralmente as atividades se limitam as modalidades que mais tradicionais, como voleibol, basquetebol e handebol (GUIOTI; TOLEDO; SCAGLIA, 2014).

Algumas propostas no campo da pedagogia do esporte (GALATTI; PAES 2006; SCAGLIA; REVERDITO; GALATTI, 2014) têm contribuído para que a iniciação esportiva possa ser a mais diversificada possível. Isso porque, além da importância de a criança poder ter contato com diversas práticas corporais e, portanto, ter um amplo "leque" de escolhas para definir suas preferências, ainda permite uma formação mais ampla das habilidades motoras e técnico-táticas delas. Para isso, essas propostas têm sugerido partir da lógica do jogo, uma vez que esses são mais gerais e não são restritas a uma modalidade específica, sendo, por conseguinte, transferíveis. Scaglia et al. (2013) explicam que a lógica do jogo são as referências funcionais (posse ou não posse da bola/implemento, regras de ação e princípios operacionais) e estruturas funcionais (companheiros, adversários, bola/implemento, espaço, regras e alvo). Isso nos mostra que as modalidades têm lógicas e elementos em comum, cujas aprendizagens são transferíveis (BAYER, 1994).

Nessa lógica, Aburachid et al. (2019) relacionam os jogos esportivos coletivos (Handebol, Rúgbi, Futebol, entre outros) com os esportes de lutas (GONZÁLEZ; DARIDO; OLIVEIRA, 2017) pela imprevisibilidade que esses jogos proporcionam. Dentre esses jogos ainda, pode-se pensar que classificá-los a partir da semeIhança entre suas lógicas internas, de modo que as modalidades esportivas que têm interação com o adversário podem ser divididas de acordo com a ação tática desenvolvida (GONZALEZ, 2004). Deste modo, essas modalidades esportivas seriam classificadas em: esportes de combate ou luta (judô, caratê, esgrima, boxe, etc.); campo e taco (beisebol, softbol, críquete); esportes de rede/quadra dividida ou muro (voleibol, tênis, tênis de mesa, badminton, squash); esportes de invasão (futsal, handebol, basquete, frisbee, rúgbi).

Por essa razão, demonstraremos nesse relato de experiência como podemos adotar, partindo das propostas da pedagogia do esporte, de ensino por meio da lógica interna do jogo, o ensino do tênis. Para isso, propusemos partir de uma série de jogos para o ensino do voleibol, ou seja, de um esporte conhecido, para alcançarmos os esportes de rede que trabalham com implemento, que não são amplamente conhecidos ou praticados. Escolhemos as modalidades de voleibol, um esporte conhecido no Brasil, e o tênis, que, apesar dos atletas conhecidos e vitoriosos, é pouco praticado no Brasil, principalmente por ser um esporte caracterizado como um esporte da elite (GONZALEZ; DARIDO; OLIVEIRA, 2017). Essas duas modalidades têm muitos elementos em comum, além da rede, são características dos jogos os adversários ficarem em lados opostos sem interação, arremessar, lançar ou bater na bola passando por cima da rede para que ela atinja o lado do adversário (GONZALEZ; DARIDO; OLIVEIRA, 2017).

Contudo é importante ressaltar que as duas modalidades têm suas lógicas que se aproximam e se distanciam. No voleibol não é permitido a bola quicar no campo de jogo, e é permitido trocar passes entre os companheiros ou companheiras. Já no tênis, o quique da bola é permitido na sua quadra de jogo, mas não é permitido trocar passes. As modalidades se diferem também no tamanho da bola de jogo e no uso do implemento.

Portanto, nosso relato justifica-se para apresentar e fortalecer a ideia da diversificação de atividades no âmbito escolar, colaborando para um maior conhecimento e possibilidades para os/as educandos/as. Este relato acrescenta possibilidades para serem ofertadas aos licenciando em EF, a fim de sensibilizá-los para atuarem com a modalidade, através de jogos baseados na lógica interna e a confecção de material alternativo aos implementos do tênis. Afinal, se os futuros professores/as não acreditarem nessa possibilidade, dificilmente atuarão com a modalidade no âmbito escolar.

\section{MÉTODOS}

Esse relato de experiência foi desenvolvido durante uma disciplina semestral de pedagogia do esporte do curso de licenciatura em educação física. Era uma turma do $6^{\circ}$ Semestre com 26 alunos/as matriculados, com características heterogêneas. Todos tiveram algum contato com modalidades esportivas, todavia, possuíam níveis de habilidades e experiências muito diferentes. Nenhum relatou ter praticado sistematicamente o tênis. Por outro lado, conheciam bastante o voleibol, esporte que também é praticado com o chão como alvo e com a quadra dividida ao meio por uma rede, por meio da qual se troca a posse de bola. A experiência aqui relatada pretendeu colaborar com a formação de professores/as de educação física para atuarem nas escolas com o ensino do tênis, uma vez que o curso não oferece uma disciplina de tênis ou esportes de rede. Nesse relato, apresentamos as atividades de voleibol e tênis que podem 
ser realizadas na prática nas escolas por meio de jogos e como foi para os alunos/as confeccionar os materiais para as aulas de tênis, para a educação física na escola.

Essa proposta está alinhada a outras iniciativas de ensinar a iniciação esportiva ao tênis a partir de sua lógica interna, como é possível ver nos manuais do Programa Segundo Tempo (GINCIENE, 2014; GINCIENE; ABURACHID, 2014); assim como em alguns artigos que pensam essa problemática no interior do ambiente escolar especificamente (KRUEGER, 2013; GINCIENE; IMPOLCETTO; DARIDO, 2017). Além disso, nosso embasamento metodológico seguiu as diretrizes das novas tendências da pedagogia do esporte (SCAGLIA; REVERDITO; GALATTI, 2014), calcadas na complexidade do jogo, manipulando com intencionalidade pedagógica - simplificando, exagerando, adaptando - a fim de desenvolver, sobretudo, a capacidade de jogar, colocando como centro, dessa maneira, os sujeitos que jogam e não os gestos padronizados e estabelecidos a priori. Em vez de repetição, preza-se pela compreensão, pela inteligência e pela criatividade, aspectos fundamentais para a tomada de decisão e para a preservação de uma das características mais caras ao jogo, a imprevisibilidade (PAES et al., 2009).

A confecção de materiais alternativos já foi sugerida por Ginciene (2014) e Ginciene e Aburachid (2014). Nessa proposta, trabalhamos em aula com raquetes de tênis emprestadas, como também propusemos, ao final, o desafio para os alunos/ as pesquisarem possibilidades de reconstrução desses materiais, visando criar um jogo possível de tênis, bem como uma maior "jogabilidade". Por jogo possível de tênis nos referimos às adaptações e transposições que realizamos para que a prática fique prazerosa e desafiadora para a capacidade de jogo de quem joga (VENDITTI JUNIOR; SOUSA, 2008). Por jogabilidade, nos referimos a qualidade dos materiais para que o jogo seja fluído e se aproxime de uma dinâmica propiciada pelos materiais oficiais.

Foram realizadas 16 horas de aula ( 8 horas de atividades práticas e 8 horas de discussões sobre as vivências e possibilidades de desenvolvimento das atividades) sobre a temática durante a disciplina. Ao final da experiência, realizamos entrevistas semiestruturadas (para que os alunos/as dessem suas opiniões com liberdade de expressar suas ideias e significados em relação ao processo que participou) com 6 alunos/as que participaram das aulas e da confecção e teste dos materiais.

Os/as alunos/as participaram voluntariamente da pesquisa. Foram realizadas perguntas para problematizar uma das questões que o tênis não é utilizado como atividade em aula, por não ter o material ou por ser muito caro. As perguntas foram "você acredita que essa adaptação dos materiais facilita o ensino da prática do tênis em aulas de Educação Física em escolas?", "o que você achou da ideia de confeccionar materiais adaptados do tênis? Dê sua opinião. Como você e o seu grupo confeccionaram os materiais? Como você se sentiu nesse processo? E durante a aula com os materiais confeccionados pela turma?

\section{Resgate do processo vivido}

Para a participação de todos os/as alunos/as simultaneamente, dividimos a quadra em seis miniquadras com largura e comprimento que variavam de $3 \mathrm{~m} \times 3 \mathrm{~m} ; 4 \mathrm{~m} \times 4 \mathrm{~m} ; 4 \mathrm{~m} \times 6 \mathrm{~m}$; demarcadas por pratinhos ou pelas próprias linhas da quadra. Para simular a rede, utilizamos bancos suecos, mesas de plástico ou colocamos cones presos com uma corda no meio. Para simular um jogo de tênis próximo a dinâmica do jogo formal, em uma aula, montamos a rede de vôlei numa altura próxima ao chão, dividida ao meio (com 3 metros de largura para cada miniquadra), a fim de fazer dois jogos simultâneos. Paralelamente, montamos duas miniquadras marcadas com bancos suecos próximo às linhas de fundo da quadra, para fazer um rodízio dos jogos entre os/as alunos/as.

Apresentamos os primeiros jogos, cujo objetivo foi desenvolver com os/as alunos/as a postura de defender o alvo (chão). Foram dois jogos que utilizamos, realizados nas miniquadras com a bola de voleibol: "Não deixe a bola cair" e o "bola sobre a rede". Após esses dois jogos, começamos a trabalhar também com o ataque ao alvo adversário, todavia, sem lançar a bola diretamente ao chão, com o jogo "voleibol com a bola agarrada". O intuito é que, ao mesmo tempo que os/as alunos/as percebem que precisam defender os espaços vazios, eles/as também começam a buscar espaços vazios do adversário/a. Em seguida, começamos a preparar mais o ataque, para dar mais tempo e atenção a tomada de decisão do ataque ao alvo adversário.

Todas essas atividades ainda utilizando a bola de voleibol ou uma bola semelhante. Nesse caso, utilizamos a rede montada mais alta, improvisada com um elástico amarrado de uma extremidade a outra da quadra, preso nas traves de futebol. Ao longo do elástico, dividimos as miniquadras, para que ocorram muitos jogos simultâneos. A ideia de começar com a rede alta é tanto para se assemelhar ao voleibol, que é uma modalidade conhecida, quanto para evitar que a bola passe muito baixa para a outra quadra e seja difícil agarrá-la ou tocá-la antes de encostar no chão.

Em seguida, trabalhamos com uma transição ao tênis, incluindo o quique no chão. É importante que os/as alunos/as percebam que o quique implica numa mudança na gestão do espaço de quadra, porque ele amplia o espaço a ser defendido, uma vez que a bola pode quicar numa linha extrema da quadra e se deslocar para longe. Por outro lado, também muda o tempo e a adaptação à bola. Começamos essas atividades usando as mãos, porque facilita o desenvolvimento do jogo neste momento, não ocorrendo tantos erros e permite observar a criatividade dos/as alunos/as em relação a tomada de decisão e entendimento do jogo. De início, o jogo parte da bola agarrada (já com bola de tênis) e depois se desenvolve para a rebatida com a própria palma da mão.

Logo depois, incluímos o implemento para que os/as alunos/as percebessem a diferença de adaptação, utilizando jogos que permitam mais tempo para ela ocorrer, bem como materiais que a facilitem. Nesse sentido, uma questão fundamental é a utilização de bolas que sejam mais lentas e que facilitem o jogo. As bolas de tênis da série "Play and Stay" da Federação Internacional de Tênis (ITF), cuja velocidade, tamanho e altura de voo variam para facilitar a aprendizagem.

Todavia, nem sempre temos esse material disponível. Para adaptarmos, utilizamos bolas de leite (de plástico) pequenas (um pouco maior que as bolas de tênis convencionais), que 'são leves e permitem ser rebatidas pela raquete e tem uma velocidade que facilita o jogo.

A seguir, no Quadro 1, apresentamos os jogos adaptados que utilizamos nas aulas. 
Quadro 1. Jogos utilizados nas aulas para o ensino do tênis.

\begin{tabular}{|c|c|c|}
\hline Jogo & Objetivo(s) Tático(s) & Descrição, orientação e variações \\
\hline $\begin{array}{l}\text { "Não deixe a } \\
\text { bola cair" }\end{array}$ & Defender o alvo (chão) & $\begin{array}{l}\text { Descrição do jogo: Jogo de } 2 \times 1 \text { ou } 3 \times 1 \text {. O jogo se desenvolve dentro das, o objetivo do jogo é trocar passes entre eles sendo que } \\
\text { uma dessas pessoas no quadrado tentará atrapalhar a troca de passes tentando intervir na trajetória da bola (de voleibol ou qual- } \\
\text { quer outra). Tamanho da quadra: Variável ( } 3 \mathrm{~m} \times 3 \mathrm{~m} ; 4 \mathrm{~m} \times 4 \mathrm{~m} \text { ) Orientações pedagógicas: Nesse jogo orienta-se que a equipe que } \\
\text { conseguir trocar mais passes sem deixar a bola cair poderá iniciar os jogos na sequência das atividades. Outra orientação é a pessoa } \\
\text { que está atrapalhando a troca de passes fique por um tempo determinado pelo professor ou professora, orienta-se no máximo de } \\
1 \text { minuto. Variação: o professor ou professora pode colocar como regra que ninguém pode ficar e receber o passe "parado", como } \\
\text { forma de estimular alunos/as a aprender a buscar a bola no ar em movimento. }\end{array}$ \\
\hline $\begin{array}{l}\text { "Bola sobre a } \\
\text { rede" }\end{array}$ & $\begin{array}{l}\text { Proteger o alvo, atacar } \\
\text { os espaços vazios e de- } \\
\text { senvolver a posição de } \\
\text { expectativa. }\end{array}$ & $\begin{array}{l}\text { Descrição do jogo: Jogo de } 3 \times 3 \text { ou } 2 \times 2 \text { ou } 1 \times 1 \text {. O jogo começa quando um aluno ou uma aluna lança a bola (de voleibol ou } \\
\text { qualquer outra) ao campo adversário (dividido em } 2 \text { partes por uma rede ou por corda) e este não pode deixá-la cair, deve agarrar a } \\
\text { bola antes que caia no chão. Não há necessidade de passar a bola para o companheiro ou companheira antes que lance a bola para } \\
\text { o campo adversário. Tamanho da quadra: Variável ( } 3 \mathrm{~m} \times 3 \mathrm{~m} ; 4 \mathrm{~m} \times 4 \mathrm{~m} \text { ) Orientações pedagógicas: Ensinar a posição de expectativa } \\
\text { (os pés afastados, um pouco à frente do outro e joelhos semiflexionados). Estimular a velocidade do jogo, quanto mais veloz eles } \\
\text { lançarem a bola mais vezes terão oportunidades de vivenciar as ações do jogo. Dar dicas para quem estiver lançando a bola buscar } \\
\text { os espaços vazios da quadra para fazer o ponto. Com o passar das ações pode-se pedir que só lancem a bola quando os jogadores } \\
\text { adversários estiverem em posição de expectativa. Orienta-se que a bola seja lançada sempre de baixo para cima. Variações: jogar } \\
\text { uma pessoa de cada vez, para aumentar o desafio. Uma opção é trocar a pessoa quando ela erra, ou marca dois pontos consecutivos } \\
\text { (a pontuação é marcada por equipe). É possível também alternar a pessoa a cada lance jogado, sendo que a pessoa que irá entrar, } \\
\text { deve se postar na linha de fundo, na posição de expectativa. }\end{array}$ \\
\hline $\begin{array}{l}\text { "Voleibol- } \\
\text { tênis" }\end{array}$ & $\begin{array}{l}\text { Aprimorar o posiciona- } \\
\text { mento para o ataque }\end{array}$ & $\begin{array}{l}\text { Descrição do jogo: Jogo de } 3 \times 3 \text { ou } 2 \times 2 \text {. O adversário lança a bola de voleibol ao campo adversário (dividido em } 2 \text { partes por uma } \\
\text { rede ou por corda), essa bola deve quicar no solo e seguir com passes diretos. A ideia do quique é poder ter o tempo de preparo } \\
\text { da equipe para promover o ataque. O jogador que receberá a primeira bola com o quique poderá se utilizar da manchete também } \\
\text { para realizar o passe. Quem não receber a primeira ou a segunda bola, deve preparar-se posicionando o corpo para atacar e deve } \\
\text { ficar com o rosto voltado para a rede e não de lado ou de costas. Tamanho da quadra: Variável ( } 3 \mathrm{~m} \times 3 \mathrm{~m} ; 4 \mathrm{~m} \times 4 \mathrm{~m} \text { ) Orientações } \\
\text { pedagógicas: é importante ressaltar o distanciamento que ocorre na lógica interna do jogo, já que o voleibol não é permitido que a } \\
\text { bola quique no seu campo de jogo. A professora e o professor devem deixar isso claro e perceber que essa estrutura de jogo é para } \\
\text { iniciantes e que ainda estão com dificuldades com a recepção e preparo para o ataque. Nesse jogo pode-se orientar para o uso da } \\
\text { manchete, importante nessa fase inicial que os próprios alunos/as descubram e tentem se orientar para o uso da manchete, e com } \\
\text { o passar do tempo da atividade os professores podem dar dicas para eles. Variação: Não foram utilizadas variações }\end{array}$ \\
\hline $\begin{array}{l}\text { "Bola no } \\
\text { espaço" }\end{array}$ & $\begin{array}{l}\text { Proteger o alvo (chão) } \\
\text { e não errar a devolução } \\
\text { da bola. Compreender } \\
\text { as opções tática de ata- } \\
\text { que do jogo. }\end{array}$ & $\begin{array}{l}\text { Descrição do jogo: } 2 \text { × } 2 \text { ou } 1 \text { x } 1 \text {. O jogo começa quando um aluno ou uma aluna lança a bola ao campo adversário e este deve tentar agarrar } \\
\text { a bola após o primeiro quique da bola. Nessa atividade se for realizado em duplas, cada um entrará no jogo uma vez, um da dupla lança e o } \\
\text { adversário tenta pegar, na próxima vez que o adversário que lançar a bola o outro companheiro ou companheira que deverá pegar a próxima } \\
\text { bola lançada e deverá lançar a bola. E assim, segue o desenvolvimento do jogo. Tamanho da quadra: Variável ( } 3 \mathrm{~m} \times 3 \mathrm{~m} ; 4 \mathrm{~m} \times 4 \mathrm{~m} \text { ) Orientações } \\
\text { pedagógicas: Ensinar a posição de expectativa. Estimular a velocidade do jogo, quanto mais veloz eles lançarem a bola mais vezes terão opor- } \\
\text { tunidades de vivenciar as ações do jogo. Dar dicas para quem estiver lançando a bola buscar os espaços vazios da quadra para fazer o ponto. } \\
\text { Com o passar das ações pode-se pedir que só lancem a bola quando os jogadores adversários estiverem em posição de expectativa. Assim, é } \\
\text { importantíssimo orientar aos alunos/as que por ser permitido o quique no tênis é interessante pensar qual posição eles devem ocupar para } \\
\text { ter um melhor desempenho no jogo. Com o passar do jogo como orientação para a expectativa, orienta-se iniciar o jogo quando o aluno } \\
\text { ou aluna estiver na posição de início de jogo, que seria próximo a linha de fundo de jogo e na sua região central. Orienta-se que a bola seja } \\
\text { lançada sempre de baixo para cima. Variações: Jogar } 1 \times 1 \text { com partidas de } 3 \text { pontos. Quando um jogador atingir essa pontuação, o jogador } \\
\text { que foi derrotado sai e entra o próximo de sua equipe. Quando um jogador ganhar duas partidas seguidas, entra o próximo de sua equipe. } \\
\text { Nesse jogo, o professor pode estabelecer as regras do jogo baseando nos critérios técnico-táticos: Exemplo: cobrar a recuperação defensiva } \\
\text { (tática) na posição de expectativa (técnica) pedindo para voltar ao centro da quadra no fundo assim que rebatê-la. Outra variação é, em vez } \\
\text { de agarrar a bola com as mãos, orientar os/as alunos/as a utilizar a rebatida com a mão ou a raquete para o primeiro toque (fazer a recepção } \\
\text { da bola) e depois agarrar a bola com as mãos, de modo a desenvolver o entendimento das duas açães fundamentais do jogo lançar (iniciar o } \\
\text { jogo) e rebater (receber a bola). }\end{array}$ \\
\hline $\begin{array}{l}\text { "Voleibol- } \\
\text { tênis" }\end{array}$ & $\begin{array}{l}\text { Aprimorar a posição de } \\
\text { expectativa defensiva e } \\
\text { buscar atacar os espa- } \\
\text { ços vazios. }\end{array}$ & $\begin{array}{l}\text { Descrição do jogo: Jogo } 2 \times 2 \text { ou } 1 \times 1 \text {. Um aluno lança a bola, e essa bola deve quicar no solo do campo de jogo da equipe adversária } \\
\text { (dividido em } 2 \text { partes por uma rede ou por corda, por pratinhos). Nesse momento, o jogador utilizará a palma da mão para rebater } \\
\text { a bola com dois contatos, o primeiro contato "amortece a bola", depois de um quique no chão, ele rebate a bola para o outro lado. } \\
\text { Quando o jogo for em duplas, um da dupla recebe a bola para a outra pessoa rebater a bola para o campo adversário. A ideia do } \\
\text { duplo contato ou passar a bola para outro componente é poder ter o tempo de preparo e melhores condições da equipe para pro- } \\
\text { mover o ataque e a defesa. Quem não receber a primeira ou a segunda bola, deve preparar-se posicionando o corpo para atacar. } \\
\text { Tamanho da quadra: Variável ( } 3 \mathrm{~m} \times 3 \mathrm{~m} ; 4 \mathrm{~m} \times 4 \mathrm{~m} \text { ) Orientações pedagógicas: Nesse jogo é importante ressaltar o distanciamento } \\
\text { que ocorre na lógica interna do jogo, já que o tênis não é permitido o duplo toque ou passar para outro componente da equipe. O/a } \\
\text { professor/a deve deixar isso claro e perceber que essa estrutura de jogo é para iniciantes e que ainda estão com dificuldades com } \\
\text { a posição de expectativa defensiva e preparo para o ataque. Variação: Com a adaptação à atividade, realizar esse mesmo jogo, mas } \\
\text { ao invés da utilização das mãos utilizar as raquetes. }\end{array}$ \\
\hline $\begin{array}{l}\text { "Tênis sem } \\
\text { saque" }\end{array}$ & $\begin{array}{l}\text { Jogar para aproximar } \\
\text { do jogo formal, }\end{array}$ & $\begin{array}{l}\text { Descrição do jogo: Jogo de } 2 \times 2 \text { e } 1 \times 1 \text {. O início de jogo é feito por uma equipe que o jogador ou jogadora fará um saque podendo } \\
\text { ser de dentro ou de fora da sua quadra de jogo e enviando a bola para o campo adversário. Os adversários devem devolver a bola } \\
\text { depois do primeiro quique ou não, e assim sucessivamente. Não é permitido segurar a bola ou realizar dois toques. A contagem e } \\
\text { regras de pontos ficam a critério dos professores/as junto às suas turmas. amanho da quadra: Variável ( } 3 \mathrm{~m} \times 3 \mathrm{~m} ; 4 \mathrm{~m} \times 4 \mathrm{~m} ; 4 \mathrm{~m} \times 6 \mathrm{~m}) \\
\text { Orientações pedagógicas: Importante ressaltar que ainda nesse momento o jogo se desenvolve sem o ataque de cima para baixo. } \\
\text { Variação: Não houve variação. }\end{array}$ \\
\hline
\end{tabular}


Além desses jogos, que foram vivenciados ao longo das aulas, no final da unidade didática, solicitamos a turma que confeccionasse raquetes e bolas de tênis que pudessem ser utilizadas nas aulas de educação física na escola. O material que deveria ser utilizado era o reciclável ou de fácil confecção, já que seriam confeccionados com as crianças nas escolas. A turma foi dividida em 4 grupos que apresentariam a sua raquete e a bola que elaboraram para a adaptação para o material. Para maior motivação, a proposta foi feita como um desafio, evidenciando que na semana seguinte, a turma inteira tentaria jogar com os materiais, que seriam avaliados pelos/as próprios/as alunos/as, tendo como critérios questões estéticas, logísticas e de dinâmica de jogo. Além de refletirem sobre a utilização de materiais adaptados e como podemos tentar desvincular a prática do tênis à elite da sociedade.

A apresentação dos materiais elaborados por cada grupo foi feita com a realização das mesmas atividades da aula anterior, porém, com as raquetes e bolas adaptadas. No Quadro 2 e na Figura 1, apresentamos as propostas de raquetes e bolas adaptadas confeccionadas pelos grupos.

Quadro 2. Materiais produzidos pelos alunos/as.

\begin{tabular}{|c|c|c|}
\hline Grupo & Materiais utilizados & Confecção \\
\hline $\begin{array}{l}\text { Raquete de velcro e espuma, } \\
\text { bola de bexiga }\end{array}$ & $\begin{array}{l}\text { Feltro, linha, velcro, enchimento } \\
\text { de fibra e pedaço redondo de } \\
\text { papelão. Para a bolinha, bolas } \\
\text { de isopor e bexiga }\end{array}$ & $\begin{array}{l}\text { Cortou-se o papelão no formato desejado e, posteriormente duas partes de feltro um pouco maior que } \\
\text { o tamanho do papelão. Depois, colocaram o papelão no meio das duas partes de feltro e costuraram as } \\
\text { extremidades. Encaixaram a ponta da alça junto com as extremidades e costuram juntas. Para fazer a alça } \\
\text { utilizaram duas faixas de feltro costuradas com velcro. Antes de terminar de costurar as extremidades } \\
\text { deixaram um pedaço aberto para encaixar o enchimento para, após costurar, finalizar. } \\
\text { Duas bolas de isopor de tamanhos diferentes e encapadas com diversas bexigas de assoprar para que elas } \\
\text { ganhassem cor e o peso desejado }\end{array}$ \\
\hline $\begin{array}{l}\text { Raquete de tampa de pote de } \\
\text { sorvete, bola de elástico }\end{array}$ & $\begin{array}{l}\text { Tampa de potes de sorvetes, } \\
\text { elásticos e bola de plástico. }\end{array}$ & $\begin{array}{l}\text { Para confecção desse material, a raquete foi adaptada para tampa de pote de sorvete, pois seria mais } \\
\text { viável para os professores de educação física usarem nas aulas. } \\
\text { A bola foi feita com uma bola de plástico de piscina infantil servindo como molde, sendo utilizados elás- } \\
\text { ticos para proporcionar o impulso do quique da bola. Para evitar que o elástico se soltasse, foi usado fita } \\
\text { em volta da bola. }\end{array}$ \\
\hline $\begin{array}{l}\text { Raquete de cabide e meia calça, } \\
\text { bolas de bexigas }\end{array}$ & $\begin{array}{l}\text { Cabide de arame; meia calça; } \\
\text { bolas de isopor; bexigas colori- } \\
\text { das; papelão; fita adesiva, cola }\end{array}$ & $\begin{array}{l}\text { Para a confecção das bolas de tênis foi utilizada duas bolas de isopor, uma grande e outra média, e be- } \\
\text { xigas. As bexigas foram cortadas na extremidade (orifício) e foram utilizadas para encapar as bolas de } \\
\text { isopor. Com isso, foi possível deixar a bola de isopor mais fofa e com capacidade de quicar maior. Para a } \\
\text { confecção da bola maior foram necessárias } 8 \text { bexigas para encapar e para a bola menor, foram necessárias } \\
13 \text { bexigas. } \\
\text { Para a confecção da raquete de cabide foi utilizado um cabide de arame e uma meia calça. O centro da } \\
\text { base do cabide foi puxado externamente, formando um desenho parecido com uma seta. Em seguida, foi } \\
\text { encaixada a perna da meia calça para cobrir a parte que foi puxada do cabide e prendendo com um nó. } \\
\text { Para a confecção da raquete de papelão foi utilizado papelão, cola e fita adesiva. Dois pedaços de papelão } \\
\text { foram recortados em formato de uma raquete e colados um ao outro para que ficasse mais firme. Após } \\
\text { isso a raquete de papelão foi encapada com fita adesiva. }\end{array}$ \\
\hline
\end{tabular}

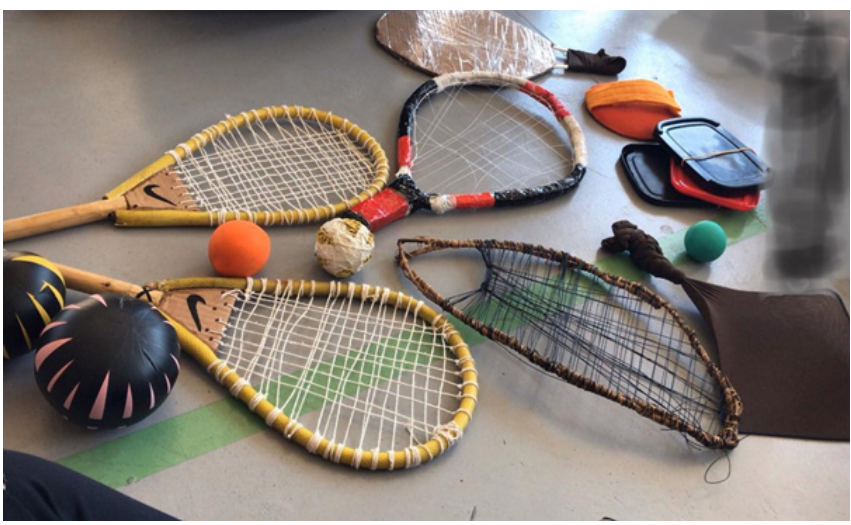

Figura 1. Raquetes e bolas confeccionadas pelos alunos/as.

\section{Sentidos atribuídos pelos estudantes à unidade didática}

Do ponto de vista dos jogos, tivemos uma resposta positiva dos discentes em relação a essa metodologia:

Acho que o sentimento foi de prazer em estar fazendo a atividade proposta, de partilhar do momento com os colegas de formação. Particularmente gosto de praticar a maioria dos esportes, então foi tranquilo participar da aula, produzir o material com os colegas e experimentar os diversificados materiais dos colegas de disciplina e formação. (J.P.Z.)
A percepção dos alunos/as corroborou com os estudos de Leonardo, Scaglia e Reverdito (2009), segundo os quais o ensino dos esportes coletivos pode ser calcado dentro das famílias de jogos, possibilitando e beneficiando o aprendizado de outras práticas. Scaglia et al. (2013) também concorda com a metodologia ao afirmar que construir uma metodologia por meio de jogos é muito razoável e destaca-se por gerar possibilidades e diversidades no conhecimento do jogo. Além disso, planejar atividades por meio deste método coloca-se a favor do aparecimento e protagonismo de novas práticas, como no nosso caso o tênis. E em alguns casos desmitificar a não prática da modalidade porque os alunos/as não gostam ou não tem interesse.

A participação nas aulas de um conteúdo não convencional e a confecção dos materiais alternativos promoveram um sentido de mobilização e de entusiasmo aos estudantes de educação física, promovendo uma aproximação positiva para a prática da modalidade:

Achei interessante, pois a presença do ensino de esportes como o tênis é quase nula na educação física escolar e os materiais são caros, ou seja, de difícil acesso, então vi a confecção de materiais para o ensino desse esporte como uma alternativa bacana. [...] entre não ter aulas de tênis por causa da falta dos recursos e ter, porém, com materiais adaptados úteis e de funcionamento semelhante ou igual, é muito melhor a segunda opção. (G.B.)

Achei muito legal, eu gostei bastante. Confesso que no início não achei tão interessante porque acreditei que todos fariam a mesma coisa, raquete de papelão e bolinhas de isopor. Mas depois que vi 
o resultado, as diferentes possibilidades de materiais adaptados, fiquei encantada com a proposta da professora. Foi muito boa a ideia. (S.A.)

Na resposta da estudante G. B. podemos verificar que o tênis é visto como um esporte caro e de elite. Por outro lado, a reflexão da estudante sobre as aulas e a confecção de material sugere que há uma alternativa que podemos seguir e utilizar para as aulas de educação física na escola. Corrêa, Freitas e Silva (2019) realizaram um estudo para verificar a inserção dos esportes de raquete no ambiente escolar e consideraram de grande valia o uso de material alternativo para as aulas de educação física escolar. Ainda segundos os autores, além da oportunidade de diversificar e ampliar os conhecimentos e habilidades dos/as alunos/as, puderam verificar a satisfação e o sentimento de sentir-se útil deles/as durante o processo. Sendo assim, é importante oportunizar vivências para os/as alunos/as aumentarem suas perspectivas e desmitificar alguns cenários, como o tênis ser apenas para a elite.

Outro aspecto relevante que é demonstrado no relato de $\mathrm{S}$. A. não só a mobilização ficou evidente, mas a satisfação de ter criado e podido fazer parte da criação da sua aula. Esse sentimento corrobora com as ideias apresentadas por Galatti e Paes (2006) como o professor deve no ambiente escolar ter o trato com o esporte, não só preocupar-se aos conteúdos técnicos/ táticos e sim favorecer a inclusão, participação e autonomia preparando-os para a sociedade.

Esses registros demonstram o quanto os licenciandos são agentes da promoção da sua formação também e podem colaborar com o desenvolvimento das aulas e dos conteúdos. Essa iniciativa de produzir as aulas, materiais e propostas em conjunto com os/as alunos/as contribui para o protagonismo e autonomia, algo muito marcante no contexto das práticas inovadoras na educação física escolar (BRACHT, 2011).

\section{CONSIDERAÇÕES FINAIS}

A possibilidade de novas formas de abordagens durantes as aulas de educação física na escola são importantes ferramentas que os professores/as podem utilizar. Notamos que as atividades foram positivas e demonstraram ser efetivas com os alunos/ as, tanto pela satisfação de encontrar novas possibilidades de ensino, quanto a participação nas atividades. A participação de todos nas atividades práticas, também demonstrou que são atividades que podem ser vivenciadas e ministradas para diferentes níveis de habilidades que encontramos no ambiente escolar.

É importante salientar que todas atividades foram mistas. Por fim, o relato tentou contribuir com os desafios e possibilidades que a educação física escolar se defronta e que com criatividade e organização as vivências para os nossos alunos/ as podem ser múltiplas.

\section{REFERÊNCIAS}

ABURACHID, L. M. C.; FRANCISCO, P. S.; SILVA, S. R.; FERREIRA, T.; GRECO, P. J. O desafio de ensinar esportes: aspectos pedagógicos a serem considerados na práxis. Corpoconsciência, Cuiabá, v. 23, n. 3, p. 122-33, 2019.

BAYER, C. O ensino dos desportos colectivos. Lisboa: Dinalivro, 1994.

BRACHT, V. Dilemas no cotidiano da Educação Física escolar: entre o desinvestimento e a inovação pedagógica. Salto para o Futuro, Rio de Janeiro, v. 21, n. 12 , p. $14-20,2011$
BRASIL . Ministério do Esporte. Diesporte: diagnóstico nacional do esporte. O perfil do sujeito praticante ou não de esportes e atividades físicas da população brasileira. Brasília: Ministério do Esporte; 2016. 70 p. (Caderno 2). Disponível em: <http://www.esporte.gov.br/diesporte/diesporte revista 2016.pdf>. Acessado: 15 de janeiro de 2019.

DIAS, J. M.; SANTOS, S. G.; SILVA, O. J.; ABES, L. O.; CARABAGIALLE, M. A. SIQUEIRA, S. G. O ensino e aprendizagem de tênis nos cursos de educação física. In: Jornada Internacional de Treinamento e Organização do Tênis, 4. Anais... Florianópolis: NETEC, 2002, p. 105-107.

GALATTI, L. R.; PAES, R. R. Fundamentos da Pedagogia do Esporte no cenário escolar. Movimento \& Percepção, Espírito Santo do Pinhal, v. 6, n.9, p. 1625, 2006.

GINCIENE, G. Tênis de campo. In: GONZÁLEZ, F. J.; DARIDO, S. C.; OLIVEIRA, A. A. B. (Org.). Esportes de marca e com rede divisória ou muro/parede de rebote. Maringá: Eduem, 2014. p. 157-205.

GINCIENE, G.; ABURACHID, L. M. C. (Org.) Esportes de marca e com rede divisória ou muro/parede de rebote. Maringá: Eduem, p. 63-109. 2014.

GINCIENE, G.; IMPOLSETTO, F. M.; DARIDO, S. C. Possibilidades pedagógicas para o ensino do tênis na escola. Conexões, Campinas, v. 15, n. 4, p. 505-21, para o 2017.
201010

GONZÁLEZ, F. J. Sistema de classificação de esportes com base nos critérios: cooperação, interação com o adversário, ambiente, desempenho comparado e objetivos táticos da ação. Lectures: Educación Física y Deportes, Revista Digital, Buenos Aires, v. 10, n. 71, 2004. Disponível em: <https://www. efdeportes.com/efd71/esportes.htm>. Acessado: 15 de março de 2020.

GONZÁLEZ, F. J.; DARIDO, S. C.; OLIVEIRA, A. A. B. Esportes de marca e com rede divisória ou muro/parede de rebote: badminton, peteca, tênis de campo, tênis de mesa, voleibol, atletismo. 2. ed. Maringá: Eduem, 2017.

GUIOTI, T. T.; TOLEDO, E.; SCAGLIA, A. J. Esportes de raquete para deficientes intelectuais leves: uma proposta fundamentada na pedagogia do esporte. Revista Brasileira Educação Física e Esporte, São Paulo, v. 20, n. 3, p. 35770, 2014.

KRÜGER, G. O tênis de campo como uma possibilidade para as aulas de educação física escolar. Cadernos de Formação RBCE, Rio de Janeiro, v. 4, n. 1, p. 60-9, 2013.

LEONARDO, L.; SCAGLIA, A. J.; REVERDITO, R. S. O ensino dos esportes coletivos: metodologia pautada na família dos jogos. Motriz, Rio Claro, v. 15, n. 2, p. 263-46, 2009.

MILISTETD, M.; DUARTE, T.; RAMOS, V.; MESQUITA, I. M. R; NASCIMENTO, J. V. A aprendizagem formal de treinadores esportivos: desafios da formação inicial universitária em educação física. Pensar a Prática, Goiânia, v. 18, n. 4, p. 982-94, 2015.

PAES, R. R.; MONTAGNER, P. C.; FERREIRA, H. B. Pedagogia do esporte: iniciação e treinamento em basquetebol. Rio de Janeiro: Guanabara Koogan, 2009.

PNUD. Programa das Nações Unidas para o Desenvolvimento. Movimento é vida: Atividades físicas e esportivas para todas as pessoas. Relatório de Desenvolvimento Humano Nacional. Brasília, 2017. Disponível em: <http:// movimentoevida.org/sumario/capitulo-4/>. Acessado em: 15 de janeiro de 2019

SCAGLIA, A. J.; REVERDITO, R. S.; LEONARDO, L.; LIZANA, C. J. R. O ensino dos jogos esportivos coletivos: as competências essenciais e a lógica do jogo em meio ao processo organizacional sistêmico. Movimento, Porto Alegre, v. 19, n. 4, p. 227-49, 2013.

SCAGLIA A. J.; REVERDITO, R. S.; GALATTI L. R. A contribuição da pedagogia do esporte ao ensino do esporte na escola: tensões e reflexões metodológicas. In: MARINHO, A.; NASCIMENTO, J. V.; OLIVEIRA, A. A. B. (Orgs.). Legados do esporte brasileiro. Florianópolis: UDSC, 2014.

SILVA, J. Esportes de raquetes: a boa prática na educação física escolar. In: BRANCHER, E. A; SALVATI, D. O. (Orgs.). Boas práticas na educação física catarinense. Florianópolis: CREF3/SC, 2019, p. 154-67.

SILVA, J. V. P.; SOUZA, L. C. L.; CALADO, K. T. O. L; SILVA, C. B.; REVERDITO, R. $S$. Família dos jogos esportivos com raquetes: metodologia e procedimentos pedagógicos. Revista Brasileira de Ciência e Movimento, Taguatinga, v. 25, n.4 p. $117-27,2017$

VENDITTI JUNIOR, R.; SOUSA, M. A. Tornando o "jogo possível": reflexões sobre a pedagogia do esporte: os fundamentos dos jogos desportivos coletivos e a aprendizagem. Pensar a Prática, Goiania, v. 11, n. 1, p. 47-58, 2008.

\section{CONFLITO DE INTERESSE}

Os autores do estudo declaram não haver conflito de interesses. 


\section{FINANCIAMENTO}

Este estudo teve apoio financeiro da CAPES (Coordenação de Aperfeiçoamento de Pessoal de Nível Superior).

\section{ORCID E E-MAIL DOS AUTORES}

Wesly Otoni Ferreira

ORCID: 0000-0001-6834-0077

E-mail: weshotoni@gmail.com

Bianca Henriques de Oliveira

ORCID: 0000-0002-6899-3622

E-mail: bianca_henriques02@hotmail.com

Vinicius do Carmo Fontana

ORCID: 0000-0003-1250-2270

E-mail:vini-tennis@hotmail.com

Mariana Zuaneti Martins (Autora Correspondente)

ORCID: 0000-0003-0926-7302

E-mail: marianazuaneti@gmail.com 